\title{
Making Smiles in the Community
}

Jordan Anderson MDH, $\mathrm{RDH}^{{ }^{*}}$ and Amanda Richardson $\mathrm{MDH}, \mathrm{RDH}^{2}$

1,2Department of Dental Hygiene Program, University of Louisiana, USA

*Correspondence Author: Jordan Anderson, Online Program Coordinator, University of Louisiana at Monroe, Dental Hygiene Department, 104 East University Avenue, Lafayette, LA 70504, USA; Tel:+13183421620; E-mail: jowilliams@ulm.edu

Received: August 28, 2019; Accepted: August 30, 2019; Published: September 03, 2019;

The Riser School Based Dental Hygiene Clinic was started in March 2006 with a grant from the Kellogg Foundation in association with the Glenwood School Based Health Clinic and the University of Louisiana at Monroe Dental Hygiene Program on the campus of Riser Elementary and Middle Schools in West Monroe, Louisiana. Initial funding paid for the renovation of a school building and purchasing of equipment and supplies. There are three dental hygiene operatories and one $\mathrm{x}$-ray operatory with a panorex machine located at the Riser School Based Dental clinic. Since 2009, the Living Well Foundation has awarded the necessary funds for project supplies and supervision to operate the Riser School Based Dental Clinic. Riser school is located in an underserved area in the West Monroe community. Above $80 \%$ of the students at Riser School are eligible for Medicaid and the free or reduced lunch program. The fall semester of 2019 will signify the beginning of University of Louisiana of Monroe's $13^{\text {th }}$ year on the Riser campus. Approximately 30 ULM Dental Hygiene students, supervised by a licensed dental hygienist, provide preventive oral health services the equivalent of 2 days a week throughout the academic year. In the past thirteen years, there have been more that 3000 dental visits at the Riser SBDHC to children ages 4-16 years old. Services provided are: $\mathrm{x}$-rays, fluoride treatments, prophylaxis, sealants, nutritional counseling, and oral health education. Each student leaves with a goody bag filled with a toothbrush, toothpaste, floss, and a prize they get to pick out of the treasure chest. For some students this is the first toothbrush they have received for their own personal use. Many times they ask for extras for their siblings or parents.

A visit to our clinic is an opportunity to change patients' views of dentistry. So many have had bad experiences because of decay and disease in their mouths that the only time they go to the dentist is when something hurts. Provision of these services meets a significant need as access to routine healthcare is limited for most of these children who may not understand the importance of good oral hygiene. In addition to seeing patients in the clinic, the ULM Dental Hygiene students go into the classrooms and conduct oral health education. Our goal is to provide a positive environment focusing on the patient individually, satisfying their oral health needs and showing them how to prevent dental diseases. Provision of these services at Riser school has several benefits: underserved children receive clinical and educational services; oral health awareness is created for the entire family; and dental hygiene students receive valuable clinical experience.

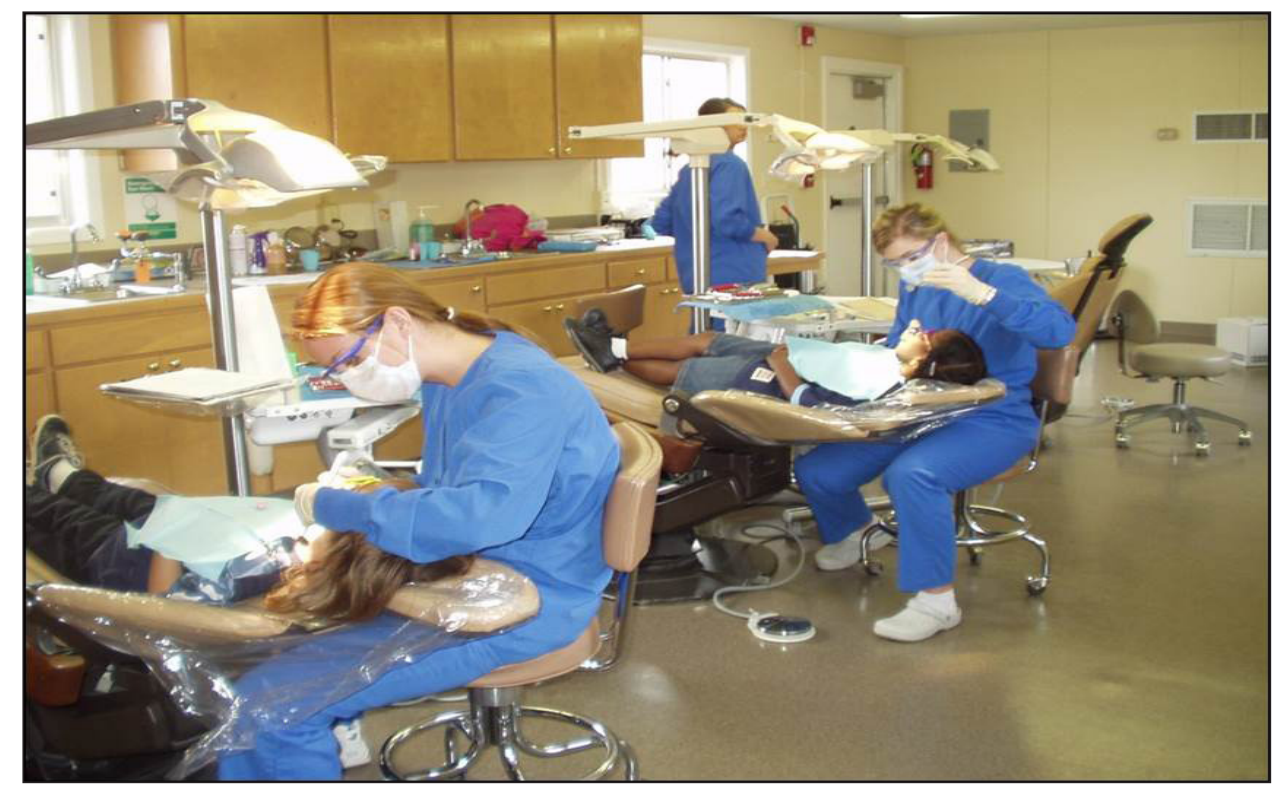

Citation:

Anderson J, Richardson A (2019) Making Smiles in the Community. J Dent Maxillofacial Res Volume 2(3): 1-1. 